\title{
Extracorporeal Support: Improves Donor Renal Graft Function After Cardiac Death
}

\author{
A. Rojas-Pena ${ }^{a, b, *}$, J. L. Reoma ${ }^{b}$, E. Krause ${ }^{b}$, \\ E. L. Boothman ${ }^{\text {, }}$, N. P. Padiyar ${ }^{b}$, K. E. Cook ${ }^{\text {, }}$ \\ R. H. Bartlett ${ }^{b}$ and J. D. Punch ${ }^{a}$ \\ a General Surgery Department, Division of Transplantation, \\ University of Michigan Health System, Ann Arbor, MI \\ and ${ }^{\mathrm{b}}$ General Surgery Department, Extracorporeal Life \\ Support (ECS) Laboratory, University of Michigan Health \\ System, Ann Arbor, MI \\ * Corresponding author: Alvaro Rojas-Pena, \\ alvaror@umich.edu \\ NIH founding: RO1HL 069420.
}

Donors after cardiac death (DCD) could increase the organ pool. Data supports good long-term renal graft survival. However, DCDs are $<10 \%$ of deceased donors in the United States, due to delayed graft function, and primary nonfunction. These complications are minimized by extracorporeal support after cardiac death (ECS-DCD). This study assesses immediate and acute renal function from different donor types. DCDs kidneys were recovered by conventional rapid recovery or by ECS, and transplanted into nephrectomized healthy swine. Warm ischemia of $\mathbf{1 0}$ and $\mathbf{3 0} \mathrm{min}$ were evaluated. Swine living donors were controls (LVD). ECSDCDs were treated with $90 \mathrm{~min}$ of perfusion until organ recovery. After procurement, kidneys were cold storage 4-6 h. Renal vascular resistance (RVR), urine output (UO), urine protein concentration (UrPr) and creatinine clearance $(\mathrm{CrCl})$, were collected during $4 \mathrm{~h}$ posttransplantation. All grafts functioned with adequate renal blood flow for $4 \mathrm{~h}$. RVR at $4 \mathrm{~h}$ posttransplant returned to baseline only in the LVD group $(0.36 \mathrm{mmHg} / \mathrm{mL} / \mathrm{min} \pm 0.03)$. RVR was higher in all DCDs $(0.66 \mathrm{mmHg} / \mathrm{mL} / \mathrm{min} \pm 0.13)$, without differences between them. UO was $>50 \mathrm{~mL} / \mathrm{h}$ in all DCDs, except in DCD-30 $(6.8 \mathrm{~mL} / \mathrm{h} \pm 1.7)$. DCD-30 had lower $\mathrm{CrCl}(0.9 \mathrm{~mL} / \mathrm{min} \pm 0.2)$ and higher $\mathrm{UrPr}$ $>200 \mathrm{mg} / \mathrm{dL}$, compared to other DCDs $>10 \mathrm{~mL} / \mathrm{min}$ and $<160 \mathrm{mg} / \mathrm{dL}$, respectively. Normothermic ECS can resuscitate kidneys to transplantable status after $30 \mathrm{~min}$ of cardiac arrest/WI.

Key words: Donor pool, donor preconditioning, early graft function, experimental models, extracorporeal membrane oxygenation, graft function, injury and preservation, ischemia time, kidney graft function, kidney, large animal model, nonbeating heart donor, normothermic recirculation, organ and tissue procurement, organ storage
Received 12 August 2009, revised 14 December 2009 and accepted for publication 10 January 2010

\section{Extracorporeal Support Improves Donor Renal Graft Function After Cardiac Death}

End-stage renal disease is treated successfully with kidney transplantation; however, this therapeutic option is limited due the shortage of organs available for transplantation. The waiting list for kidney transplants in the United States reached more than 82500 patients in 2008, despite a $30 \%$ increase in the number of renal transplants performed in 2007 (16 628) compared to 10 years ago (11 703). In 2007, a vast majority of transplanted renal grafts were from donors after neurologic determination of death (DND), or brain dead donors, with a significant portion (6041) from living donors (1).

The use of organs recovered from donors following circulatory determination of death (DCD) — previously known as non-heart beating donors-has the potential to increase the donor pool; but currently accounts for less than $8 \%$ of all organ transplants (2). The reason is that organs taken by 'rapid recovery' from DCD donors do not function as well as organs from DND, especially initially. Poor immediate graft function can be tolerated for renal transplants because of renal replacement therapies like dialysis, so almost all organs from DCD are kidneys. The incidence of delayed graft function and primary graft nonfunction for kidneys from $D C D$ is significantly higher than kidneys from DND, in some series more than double $(3,4)$. This is presumed to be due to the warm ischemic and hypoxic injury that inevitably occurs following withdrawal of life support until the organs are cold perfused.

The use of normothermic venoarterial extracorporeal membrane oxygenation support (hereafter called ECS) after cardiac arrest restores circulation of warm oxygenated blood to the abdominal organs. It can be initiated immediately following declaration of death. Experimental data from our lab has shown that kidney and liver function returns and is maintained while on ECS (5). In animals, perfusing with warm oxygenated blood has been shown experimentally to increase the energy charge (ADP) and antioxidant levels in the recovered organs $(6,7)$. By restarting circulation after cardiac arrest, the agonal, hypoxic and ischemic events 


\section{Rojas-Pena et al.}

surrounding death and subsequent reperfusion can be turned into an ischemic preconditioning phenomenon (8).

In our clinical experience the donor pool was expanded by $33 \%$ by establishing normothermic, oxygenated blood perfusion of abdominal organs using ECS shortly after circulatory determination of death. Moreover it allowed for controlled, unhurried organ procurement; delayed graft function was developed in only two grafts (8\%) (9).

The use of DCD grafts is encouraged in all the US transplant programs, but there is hesitation among clinical personnel due to uncertainty about the immediate and longterm outcomes of these grafts, especially when the organs come from DCD donors that also fit criteria for expanded criteria donors (ECD). These donors are over 60 years of age or over 50 years of age with a history of hypertension, poor renal function at the time of recovery, or death due to cerebrovascular accident. While ECS-DCD offers potentially improved results, it is also perceived as costly. However, if ECS-DCD can improve initial graft function, the cost of ECS is offset by the reduced hospital stay and need for dialysis if the kidneys function immediately. We developed an animal study to assess the immediate renal graft function from DCD donors under various warm ischemia times. This study was designed to evaluate ECS compared to rapid recovery in a swine model of renal transplantation after DCD.

\section{Material and Methods}

This study was approved by the University of Michigan University Committee on Use and Care of Animals (UCUCA). All pigs received humane in compliance with the Guide for the Care and Use of Laboratory Animals.

\section{Experimental design}

Using a standard swine model of cardiac death and warm ischemia, kidneys were removed by conventional rapid recovery or ECS, stored for $4-5 \mathrm{~h}$ cold ischemia, transplanted into nephrectomized swine recipients. Warm ischemia times of 10 and 30 min were compared. Kidneys transplanted from living donors (LVD) served as a control group. Five groups of 5 animals each were compared as shown in Table 1.

\section{Animal model}

The following model was used in all experiments. Female swine (weighing 25-30 kg), were sedated with an intramuscular (i.m) mix of $5 \mathrm{mg} / \mathrm{kg}$ Tiletamine $\mathrm{HCl}$ and Zolepam $\mathrm{HCl}$ (Telazol, Wyeth Holdings Corporation; Carolina, Puerto Rico) and 3 mg/kg Xylazine (TranquiVed Vedco, St. Joseph,
MO). Swine were intubated and mechanically ventilated (MV) with $100 \%$ $\mathrm{O}_{2}$ and $1-3 \%$ Isofluorane (Hospira, Lake Forest, IL). Initial MV settings were adjusted to maintain $\mathrm{pCO}_{2}$ between $35-45 \mathrm{mmHg}$, and peak inspiratory pressures $<25 \mathrm{cmH}_{2} \mathrm{O}$. The right carotid artery and right internal jugular vein were catheterized to monitor arterial blood pressure and heart rate and to collect blood samples. A CCOmbo-CCO/SvO 2 NIP pulmonary artery catheter (Edwards Lifesciences, Irvine, CA) was placed via the internal jugular vein for administration of fluids and monitoring of cardiac output and central venous pressure. At the end of surgical instrumentation and prior to baseline data collection, a 20 min acclimation period was allowed for all animals.

\section{Donor models}

1. LVD model: $100 \mathrm{U} / \mathrm{kg}$ Heparin Sodium (APP Pharmaceuticals; Schaumburg, IL) was administered 5 min before proximal ligation of the renal artery. The kidneys were subsequently resected, flushed with 300-500 mL of Custodiol (Methapharm Inc, Brantford, ON, Canada), and stored cold for $4-5 \mathrm{~h}$ before transplantation.

2. DCD model: Anesthetized pigs were paralyzed using Pancuronium Bromide (Hospira) and cardiac death was achieved by apnea. The agonal period was $17 \pm 1.8 \mathrm{~min}$, simulating at some extent the clinical reality. Circulatory death was defined as: asystole or pulse-less arrhythmia with a pulse pressure less than $15 \mathrm{mmHg}$. After death, warm ischemia (WI)/asystole times of 10 and 30 min were examined. These times are two and six times longer than the 5 min period that is frequently used in the United States as a 'no touch' period. To achieve anticoagulation, heparin $(100 \mathrm{U} / \mathrm{kg})$ was administered $1 \mathrm{~min}$ after withdrawal of respiratory support. Kidneys were then recovered in one of the following ways

a. Rapid recovery/Conventional: After death, a midline laparotomy was performed to obtain access to the kidneys. The vessels were identified and surrounding soft tissue was dissected. After a period of 10 or $30 \mathrm{~min}$ of warm ischemia, the pig was cooled via ice in the abdominal cavity, followed by rapid removal of the renal grafts. Grafts were managed as in the LVD protocol with immediate cold perfusion and storage.

b. ECS procurement: After death, both external jugular veins were cannulated with two 20-23 Fr venous cannulae (to obtain access to the RA), and a 14-16 Fr arterial cannula was advanced into the abdominal aorta via right iliac or femoral artery. The V-A ECS circuit animal model is represented in Figure 1, include: a roller pump (Cobe Cardiovascular, Lakewood, CO), an external heat-exchanger (Seabrook Medical System, Cincinnati, $\mathrm{OH}$ ), and a membrane oxygenator (Affinity. NT, Medtronic; Minneapolis, MN; Rochester, NY) and then stepped up to $3 / 8$ " tubing to connect them to the oxygenator outlet. Pump flows were continuously monitored using a T208 monitor (Transonic System, Ithaca, NY). The membrane oxygenator was primed with saline and $50 \mathrm{mEq}$ of $\mathrm{HCO}_{3}$ and maintained at $38^{\circ} \mathrm{C}$. After 10 or $30 \mathrm{~min}$ of WI venoarterial perfusion was begun and maintained at $50 \mathrm{cc} / \mathrm{kg} / \mathrm{min}$ for 90-100 min, aiming to maintain a CVP between $7-16 \mathrm{cmH}_{2} \mathrm{O}$ during

Table 1: Donor type and characteristics

\begin{tabular}{|c|c|c|c|c|c|}
\hline Donor type & Group name & $\begin{array}{l}\text { Warm } \\
\text { ischemia }\end{array}$ & $\begin{array}{l}\text { Procurement } \\
\text { technique }\end{array}$ & $\begin{array}{c}\text { Cold } \\
\text { ischemia }\end{array}$ & (n) \\
\hline Living donor & LVD & $<1 \min$ & Standard & $4-5 \mathrm{~h}$ & 5 \\
\hline \multirow[t]{2}{*}{$\mathrm{DCD}$} & DCD $10 \mathrm{~min}$ & $10 \mathrm{~min}$ & Rapid raceway & $4-5 \mathrm{~h}$ & 5 \\
\hline & DCD30 min & $30 \mathrm{~min}$ & Rapid leeway & $4-5 h$ & 5 \\
\hline \multirow[t]{2}{*}{ ECS-DCD } & ECS-DCD $10 \mathrm{~min}$ & $10 \mathrm{~min}$ & 90 min ECS & $4-5 h$ & 5 \\
\hline & ECS-DCD $30 \mathrm{~min}$ & $30 \mathrm{~min}$ & 90 min ECS & $4-5 h$ & 5 \\
\hline
\end{tabular}

$\mathrm{LVD}=$ living donors $; \mathrm{DCD}=$ donors after cardiac death; $\mathrm{ECMO}=$ extracorporeal membrane oxygenation. 


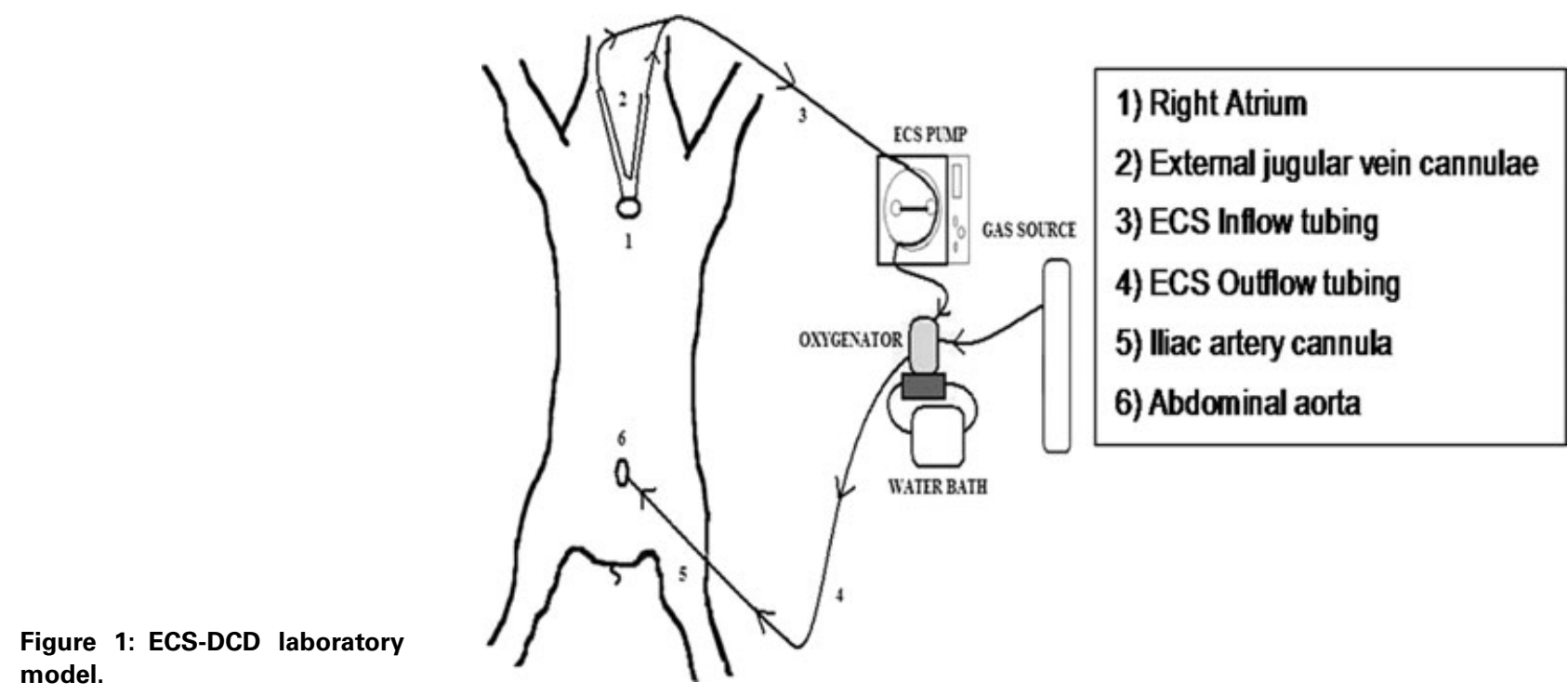

ECS, avoiding cavitation or hemodilution (targeting hematocrit value $>23 \%$ ). The kidneys were removed while warm perfusion continued, and managed as in the LVD protocol with immediate cold perfusion and similar storage time.

\section{Recipient model}

Healthy swine underwent surgical instrumentation as described above plus bilateral nephrectomies. After removal of one kidney, a perivascular renal (Transonic System, Ithaca, NY) flow probe was placed to obtain measurement of normal renal blood flow to the contralateral kidney for baseline. A blood sample was collected, and urine output was quantified and collected for determination of creatinine and protein concentration. The donor kidney was implanted and the remaining kidney was removed. The inferior vena cava and infrarenal abdominal aorta were prepared for side-to-end vascular anastomosis of the experimental renal graft. Heparin (100 U/kg) and $125 \mathrm{mg}$ of methylprednisolone (Solumedrol, Pharmacia \& Upjohn, New York, NY) were administered 5 min before surgical anastomosis. A catheter was advanced in the ureter for urine output collection. The pig remained under anesthesia for the entire experiment. For all recipients, maintenance i.v fluid was 120-150 mL/h, plus 1:1 replacement of urine output with NSS, maintaining CVP between $12 \pm 3 \mathrm{cmH}_{2} \mathrm{O}$

\section{Data acquisition}

Data collected during the experiment are summarized in Table 2. Baseline $(B L)$ data were collected on the single recipient kidney after surgical instrumentation but before implantation of renal grafts.

\section{Data analysis}

Renal vascular resistance (RVR) was calculated using the following equation: RVR = (MAP-CVP)/RAF. Creatinine clearance $(\mathrm{mL} / \mathrm{min})$ was calculated using the following equation: $\mathrm{CrCl}=([\mathrm{U}] \times(\mathrm{UO} / 60)) /[\mathrm{P}]$, in which $[\mathrm{U}]=$ urine concentration of creatinine, $[\mathrm{P}]=$ plasma concentration of creatinine, and $\cup O=$ urine output in $\mathrm{mL} / \mathrm{h}$. Urine was collected continuously from the ureter, during the total length of the study $(4 \mathrm{~h})$. This measurement is not affected by serum concentration of creatinine because it did not change significantly during the collection period. A mixed model analysis was performed within SPSS 17.0 (Chicago, IL) to examine the effect of procurement technique on all acquired data. The pig/experiment number is the repeated measure variable, and the independent variables were the experimental group, and the experimental time. The dependant variables were recipient hemodynamics (MAP, CVP), renal hemodynamics (flows, resistance), $\cup \mathrm{O}, \mathrm{CrCl}$ and urine protein concentration. Last, post hoc analysis using a Bonferroni-corrected confidence interval was used to determine

Table 2: Data acquisition

\begin{tabular}{|c|c|c|}
\hline Variable Type & Frequency & Description \\
\hline $\begin{array}{l}\text { Renal } \\
\text { Hemodynamics }\end{array}$ & $\begin{array}{l}\text { Recorded every } 30 \text { min } \\
\text { after transplantation }\end{array}$ & $\begin{array}{l}\text { MAP: mean arterial pressure; CVP: central venous } \\
\text { pressure; RAF: renal artery flow; RVR: renal vascular } \\
\text { resistance }\end{array}$ \\
\hline Renal function & $\begin{array}{l}\text { Baseline and every } 1 \mathrm{~h} \\
\text { after transplantation }\end{array}$ & $\begin{array}{l}\text { Urine output (UQ); urine protein } \\
\text { concentration (UrPr) }\end{array}$ \\
\hline Venous \& arterial & Baseline, end of CA, every & Blood $\mathrm{pH} ; \mathrm{pCO}_{2} \mathrm{pO}_{2} ;$ hemoglobin; \\
\hline Blood gases & $1 \mathrm{~h}$ after transplantation & $\begin{array}{l}\text { hematocrit; oxyhemoglobin saturation; electrolytes }(\mathrm{Na}, \mathrm{K} \text {, } \\
\left.\qquad \mathrm{Ca}, \mathrm{Cl} \text { and } \mathrm{HCO}_{3}\right)^{* *}\end{array}$ \\
\hline Chemistry panel & $\begin{array}{l}\text { Baseline; immediately } \\
\text { after reperfusion, and } 4 \mathrm{~h} \text { after } \\
\text { traınsplantation. }\end{array}$ & $\begin{array}{l}\text { Plasma creatinine; BUN and ADL; urine } \\
\text { creatinine; BUN and protein. } * * *\end{array}$ \\
\hline
\end{tabular}

*BIOPAC Systems, Goleta, CA; ** Radiometer A/S, Copenhagen NV Denmark; ***Animal Diagonostic Lab of the University of Michigan. 
Rojas-Pena et al.

Table 3: Graft cold ischemia time and DCD-ECS run characteristic

\begin{tabular}{|c|c|c|c|c|c|}
\hline \multicolumn{6}{|c|}{ Average graft cold ischemia time per donor group in minutes } \\
\hline LVD & DCD $10 \mathrm{~min}$ & DCD $30 \mathrm{~min}$ & & ECS-DCD $10 \mathrm{~min}$ & ECS-DCD $30 \mathrm{~min}$ \\
\hline $288.7 \pm 11.8$ & $266.0 \pm 18.9$ & $262.6 \pm 11.9$ & & $263.0 \pm 11.9$ & $265.8 \pm 10.7$ \\
\hline \multicolumn{6}{|c|}{ DCD-ESC run characteristics ( $n=3$ ) } \\
\hline & ECS-DCD group & Baseline & $30 \min$ ECS & $60 \min$ ECS & $90 \mathrm{~min}$ ECS \\
\hline \multirow[t]{2}{*}{$\mathrm{MAP}(\mathrm{mmHg})$} & $10 \mathrm{~min}$ & $67.3 \pm 5.7$ & $48.3 \pm 6.2$ & $70.3 \pm 13.6$ & $76.3 \pm 9.9$ \\
\hline & $30 \mathrm{~min}$ & $76.3 \pm 5.0$ & $41.6 \pm 8.4$ & $46.0 \pm 7.5$ & $51.0 \pm 10.6$ \\
\hline \multirow[t]{2}{*}{ ECS flows (L/min) } & $10 \mathrm{~min}$ & N/A & $1.6 \pm 0.5$ & $1.6 \pm 0.5$ & $1.7 \pm 0.4$ \\
\hline & $30 \mathrm{~min}$ & N/A & $1.6 \pm 0.1$ & $1.75 \pm 0.01$ & $1.7 \pm 0.2$ \\
\hline \multirow[t]{2}{*}{ CVP $\left(\mathrm{cmH}_{2} \mathrm{O}\right)$} & $10 \mathrm{~min}$ & $13.0 \pm 1.8$ & $12.7 \pm 2.8$ & $9.2 \pm 3.6$ & $9.1 \pm 3.3$ \\
\hline & $30 \mathrm{~min}$ & $10.4 \pm 0.5$ & $10.1 \pm+4.4$ & $11.1 \pm 3.2$ & $8.3 \pm 2.0$ \\
\hline \multirow[t]{2}{*}{ Hematocrit \% } & $10 \mathrm{~min}$ & $31.6 \pm 1.5$ & $28.4 \pm 2.0$ & $32.4 \pm 1.8$ & $34.8 \pm 3.3$ \\
\hline & $30 \mathrm{~min}$ & $33.8 \pm 0.6$ & $30.1 \pm 0.6$ & $24.6 \pm 1.5$ & $28.4 \pm 2.2$ \\
\hline
\end{tabular}

differences between experimental groups. Values of $p<0.05$ were considered statistically significant. Results are expressed as mean values with errors bars representing standard error. At the end of the study, the entire kidney was removed for histopathology; two, $2 \mathrm{~cm} \times 2 \mathrm{~cm}$ tissue samples were placed in formalin. The histoslides were processed by the University of Michigan Unit for Laboratory Animal Medicine, and read by a blinded pathologist.

\section{Results}

All grafts were successfully transplanted into each healthy but nephrectomized swine recipient. Average cold storage times per group and ECS-DCD perfusion characteristics are summarized in Table 3.

\section{Recipients systemic hemodynamics}

In all experimental groups, mean arterial pressure (MAP) was kept between 60-90 $\mathrm{mmHg}$ as shown in Figure 2; and CVP was maintained between $12 \pm 3 \mathrm{cmH}_{2} \mathrm{O}$ during the whole experimental time in all groups. In most cases, MAP was maintained at baseline levels. However, MAP decreased significantly ( $p<0.05$ ) immediately after reperfusion in the DCD 30 min group. This decrease in MAP resolved after approximately 5 min of reperfusion and returned to baseline values by the 30 min data point. After this point there were not significant differences between groups.

\section{Renal hemodynamics and function}

Renal artery flow (RAF) following transplantation was higher at the end of the experiment in the group that received grafts from LVD ( $p<0.05$ ) compared to all DCD groups (Figure 3). RAF was lower only in the DCD-10 min group through all the experimental time, compared to other DCD groups.

As expected renal vascular resistance (RVR) Figure 4, correlated with RAF. It increased significantly immediately after reperfusion in all groups due to cold preservation, and returned to normal only in the LVD group ( $p<0.05)$. In the other four groups, RVR was slightly higher than normal, baseline values during the whole experiment, without significant differences between them.

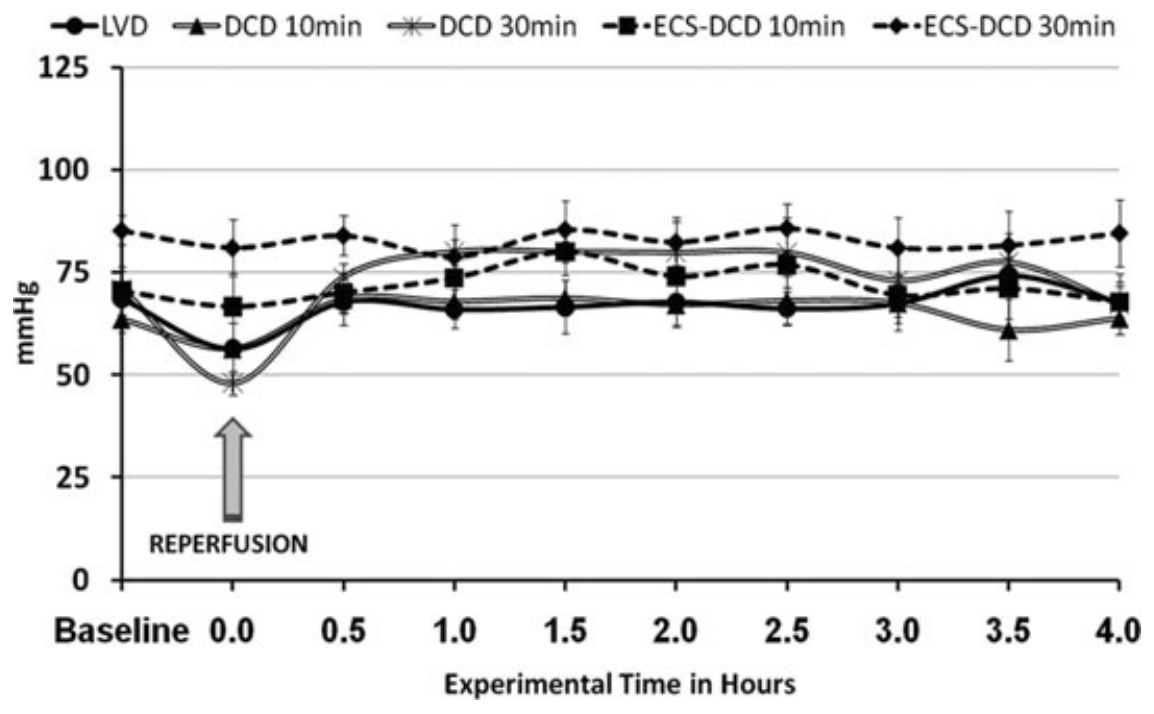

Figure 2: Recipients mean artial pressure (MAP). Error Bars = SEM/ $(n=5)$. 
Figure 3: Recipients renal artery blood flow (RAF). Error Bars = $\mathrm{SEM} /(\mathrm{n}=5)$

Urine Output is represented in Figure 5. Although all groups had some urine output, the amount produced in the DCD-30 min group was minimal $(6.8 \pm 1.7 \mathrm{~mL} / \mathrm{h})$, and significantly less than in the other groups that all had urine output of more than $50 \mathrm{~mL} / \mathrm{h}$ by the fourth hour.

Creatinine Clearance $(\mathrm{CrCl})$ is represented in Figure 6: $\mathrm{CrCl}$ was significantly lower ( $<0.05$ ) in the DCD-30 group $0.9 \pm 0.2 \mathrm{~mL} / \mathrm{min}$, compared to the other groups after $1-\mathrm{h}$ posttransplant. Only grafts from the LVD group returned back to normal values ( $\sim 25 \mathrm{~mL} / \mathrm{min})$ after $4 \mathrm{~h}$ of reperfusion. The DCD-30 min group had significantly lower $\mathrm{CrCl}$ at 1 and 4-h posttransplantation, compared to all the groups. In particular, when ECS support was used, after 30 min of warm ischemia (ECS-DCD $30 \mathrm{~min}$ ), the $\mathrm{CrCl}$ was similar to those DCD that sustained only $10 \mathrm{~min}$ of warm ischemia.

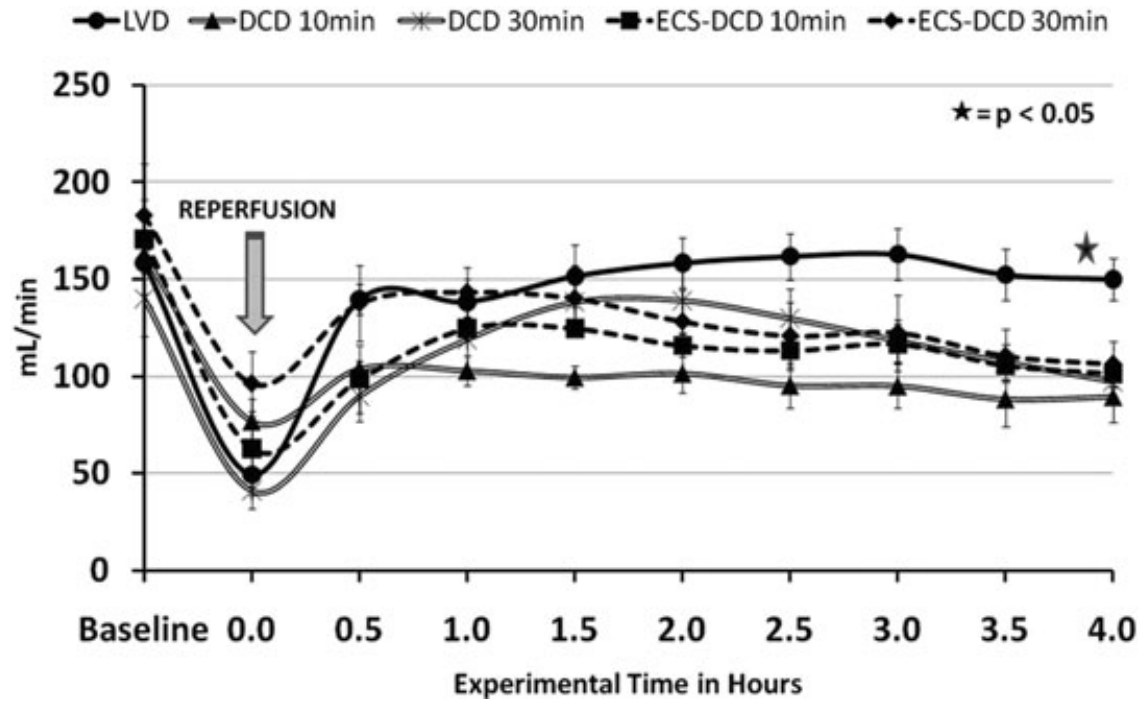

Urine protein concentration ( $\mathrm{UrPr}$ ) at 1 and $4 \mathrm{~h}$ following reperfusion is represented in Figure 7. UrPr was significant higher $(p<0.05$ ) in the DCD 30-min group compared to all other groups where normal values for healthy swine of this size were evident at the end of the experimental time.

\section{Renal pathology}

A summary of the pathologic findings from renal tissue collected at the end of the experiment can be found in Table 4. Grafts from DCD 30 min shown some signs of reversible acute tubular necrosis. No infarcts were seen.

\section{Discussion}

The increasing gap between organ demand and organ sources has led the medical community to go back to the
Figure 4: Calculated renal vascular resistance (RVR). Error Bars = $\mathrm{SEM} /(\mathrm{n}=5)$.

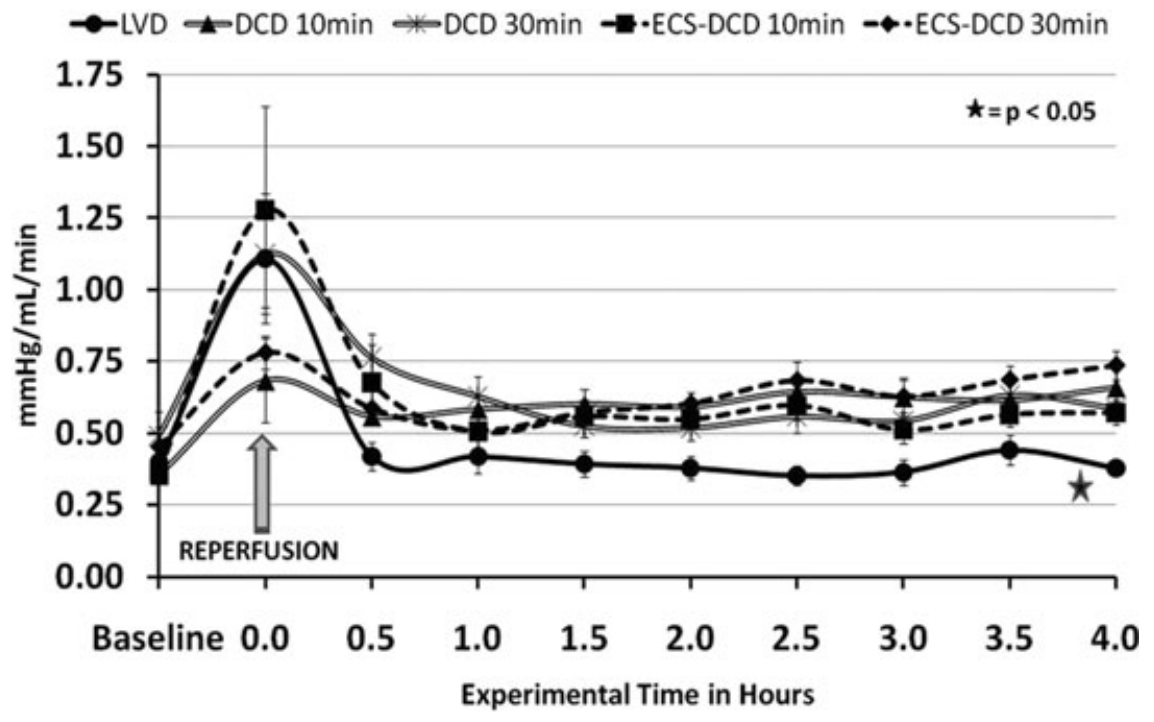




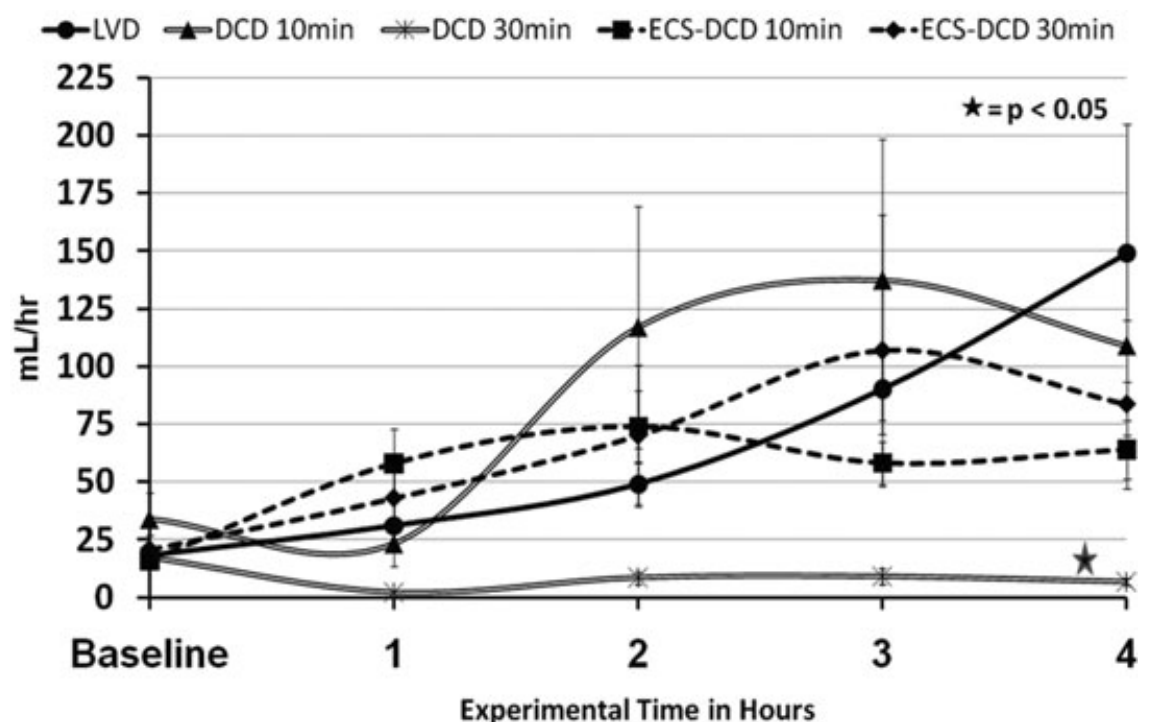

Figure 5: Recipients urine output (UO). Error Bars $=\mathrm{SEM} /(\mathrm{n}=5)$. way that grafts were procured in the early days of transplantation through the use of grafts from DCD. However renal grafts from DCD are associated with higher rates of delayed-graft function, primary graft-non-function and, in some series, long-term graft survival (10-12).

After procurement with conventional techniques (rapid recovery) renal grafts had different outcomes directly related to the extent of warm ischemia time. In 1995, Chang et al. (13), reported $26 \%$ of PGNF (excluding rejection) when organs from nonheart beating donors (NHBD) were used. More recently the rates of PGNF in renal grafts are: LVD $2 \%$, brain dead/heart beating donors 3\%, and NHBD $7 \%$. The rate of DGF after rapid recovery is $40-50 \%$. The rates of DGF in kidneys from heart-beating donors is $25-30 \%$, significant lower compared to DCD organs. $(4,11,14,15)$ Despite higher rates of DGF reported when kidneys from
DCD are used the long-term survival rates some reports show graft survival that is similar to heart-beating donors at 2, 4 and 6 years (16-24).

Due to the poor outcomes when DCD grafts were used, ex-vivo perfusion with a cold acellular solution is often used to measure renal vascular resistance in the donor kidney. This method allows transplant centers to identify grafts with elevated resistance and these kidneys were simply discarded. When implemented, the rates of PGNF were reduced to as little as 5\% (25). The use of this technique became standard in many DCD programs (26-28).

Hypothermic extracorporeal support has been used in association with rapid recovery. Koyoma et al. used cardiopulmonary bypass at $18^{\circ} \mathrm{C}$ and reported high rate of DGF in kidneys subjected to long periods of warm ischemia (29

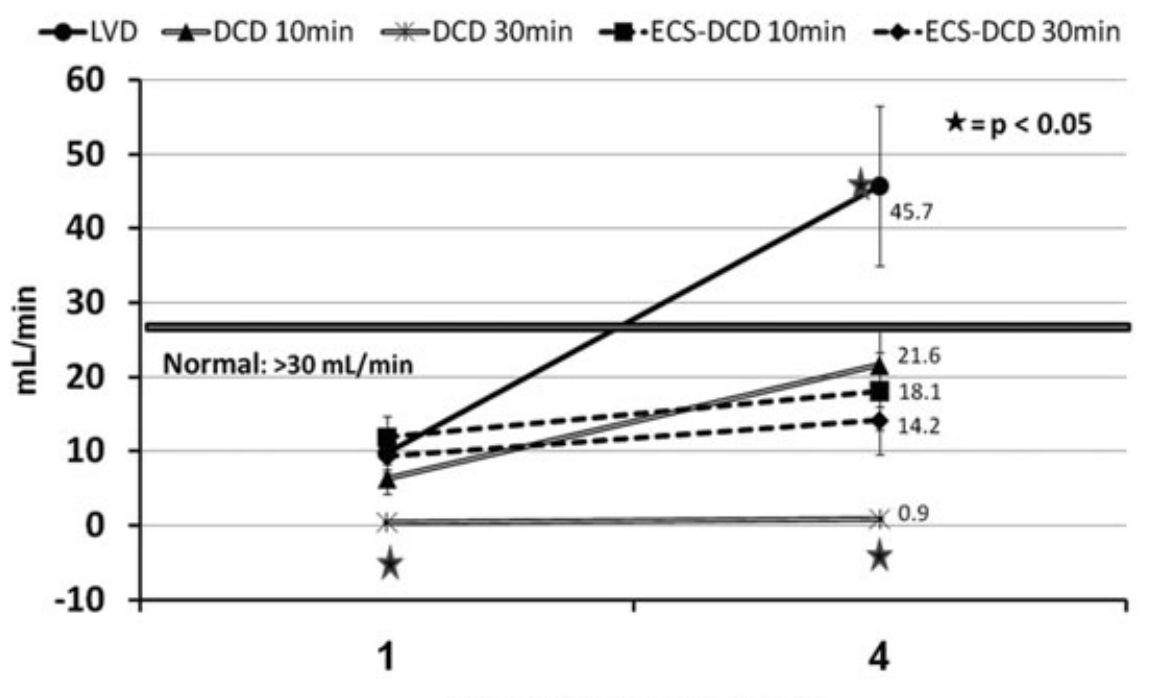

Experimental Time in Hours
Figure 6: Recipients measurement of $\mathbf{C r C l}$. Error Bars = SEM/(n=5). 
ECS Effects on Renal Function in DCD Grafts

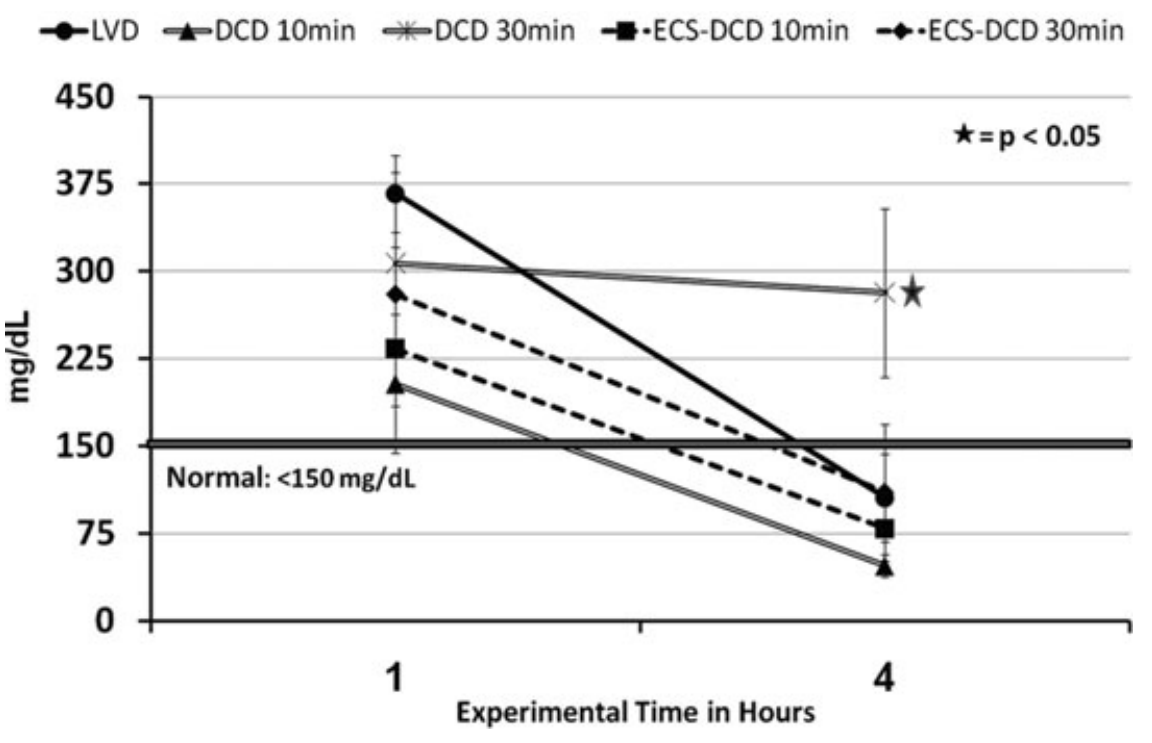

Figure 7: Recipients urineprotein concentration (UrPr). Error Bars = $\mathrm{SEM} /(\mathrm{n}=5)$.

out of 32 kidneys) but similar long-term survival rates compared to other type of donors (29). The transplant group from The National Taiwan University Hospital, used VA perfusion with oxygenation (ECS) at $4{ }^{\circ} \mathrm{C}$. They reported $66 \%$ of immediate graft function, and $33 \%$ incidence of DGF that resolved with short-term (1-2 weeks) hemodialysis therapy (30-32). A group from Japan used rapid cooling techniques to procure organs from DCD obtaining similar results $(12,20,32,33)$.

A transplant group in Spain has reported using normothermic ECMO perfusion to support the potential donor until organ procurement (34). In 2000, Valero et al. reported significantly lower rates of DGF (13\%) and no PGNF in kidneys from DCD when ECMO was used during organ donation in DCD (21). Our group at the University of Michigan Hospital, uses normothermic ECMO in DCD Maastricht type II and IV donors and reported low rates of DGF (8\%), no PGNF, and an increment of the organ pool at our institution by $33 \%(9,21,35)$.

Almost all the studies on DCD kidneys are based on 5 min of warm ischemia after cardiac arrest. This study evaluated the effectiveness of ECS during organ procurement after longer periods of cardiac arrest/warm ischemia time. The results indicate that implementation of ECS in the donor during organ procurement can resuscitate kidneys to transplantable state with immediate graft function after $30 \mathrm{~min}$ of warm ischemia. The use of standard rapid recovery technique that is the most common method to procured DCD organs effectively resuscitated renal grafts after $10 \mathrm{~min}$ of warm ischemia, but not after 30 mins. ECS may be useful in situations where prolonged ischemia is probable including Maastricht type 1 and 2 donors ('uncontrolled') and situations where local practice involves withdrawal of support in a setting other than in the operating suite. We used $37^{\circ} \mathrm{C}$ (normothermic) perfusion in these experi- ments because the best clinical results were achieved at normothermia.

In this study, 90-100 min of ECS was used to perfuse the donors because it represents our standard clinical and laboratory practice $(5,9)$. Current studies in our laboratory assess the effects of longer ECS runs during the procurement of abdominal organs. Despite the difference of warm ischemia (10 min and $30 \mathrm{~min}$ ) in the two groups in which ECS was implemented for organ recovery there were no significant differences between ECS perfusion flows between them. Postreperfusion renal arterial flow was achieved in all transplanted kidneys, indicating no complications during vascular anastomosis, but normal values were only achieved in the LVD group. Renal flow and function, as measured by urine output, urine protein and creatinine clearance, was adequate during the first $4 \mathrm{~h}$ posttransplant after 10 min of warn ischemia with or without ECS, indicating kidneys could probably be recovered from clinical DCD donors after 10 min of warm ischemic arrest. However, in the groups that sustained longer cardiac arrest times (30 min), kidney function was established only when ECS was used during organ procurement. ECS helps in the correction of the acidosis before cold ischemia, restores ATP levels, regulates calcium homeostasis, and removes locally (renal) formed free radicals, in the donor and before cold storage. It is possible that ECS plays an important role in the preconditioning of organs before cold storage; this may explains why ECS resuscitated kidneys after 30 min of arrest/ischemia (36). This observation, suggests that ECS has a protective role following a moderately severe ischemic insult, and may allow organs to recover from prolonged warm ischemia injury during donor reperfusion prior to cold preservation/storage.

Limitations of this study are: (1) the swine model of cardiac arrest does not exactly mimic the clinical situation. The 


\section{Rojas-Pena et al.}

Table 4: Histopathology of renal grafts

\begin{tabular}{lll}
\hline Group & Histoslide & Characteristics \\
\hline LVD & tubules and blood vessels. & Normal capsule, glomeruli, \\
& &
\end{tabular}

DCD 10 min ECS-DCD $10 \mathrm{~min}$ ECS-DCD $30 \mathrm{~min}$

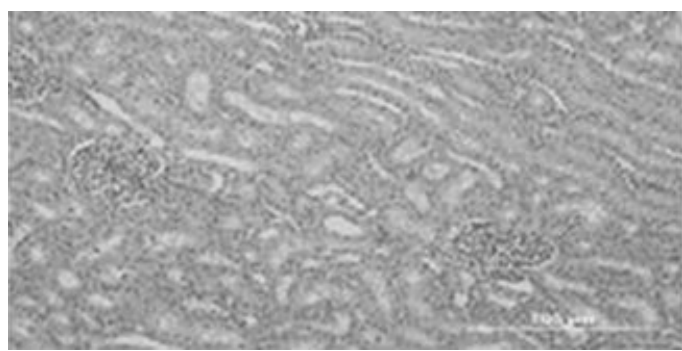

DCD 30 min

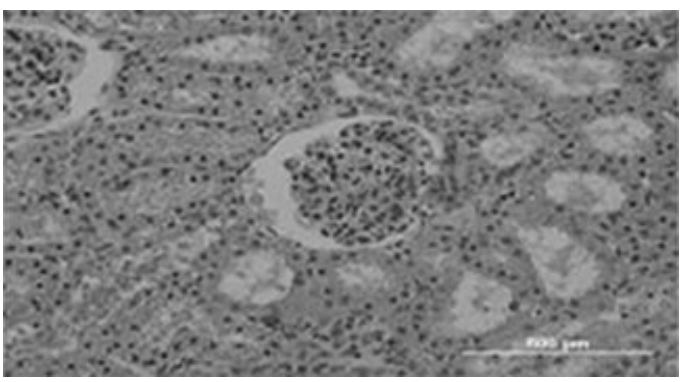

Mild mesengial cellularity was observed with focal protein casts in the tubules, no signs of ATN were observed. model is both an asset and a limitation of this study. Cardiac arrest by apnea in the swine is a very reproducible model that permits evaluation of the variables in a standardized fashion. However, many potential uncontrolled DCD subjects will have a prolonged period of attempted resuscitation by CPR and ventilation including many resuscitative drugs. We acknowledge this limitation, but we argue that the details of ECS must be characterized in the apneic arrest model before adding the variables of CPR and donor treatment; (2) The ECS cannulae used for blood inflow into the circuit were placed into the EJV, due to the limited size of the femoral vein in these size pigs; but we believe that the insertion site of the cannulae did not affect the results. Also, an intrathoracic balloon was not used in these studies, but it will be implemented in our DCD model for further studies with the goal of isolating the brain from the circulation; (3) Grafts function were not evaluated beyond $4 \mathrm{~h}$. The swine model simulates the agonal period in 'controlled' DCD, but is certainly less variable than observed in clinical practice. We did not evaluate graft function beyond $4 \mathrm{~h}$ to avoid the problems of animal recovery and graft rejection. Kidneys that did not function immediately might recover with longer time (as in DGF). Conversely, kidneys that function immediately after transplant will function indefinitely depending on prevention of rejection; (4) $\mathrm{CrCl}$ was measured using a 4-h timed collection, not the clinical standard based on a 24-h urine sample collection, but Bloor et al., proposed that when healthy subjects with normal renal function preoperative (such as the scenario of our study) are used a 4- $\mathrm{h} \mathrm{CrCl}$ prediction method correlates with $\mathrm{CrCl}$ measurement (37).

In a different model, we have reported that room temperature perfusion is equivalent to perfusion at $37^{\circ}$. We have also reported that heparin given 5 min after arrest (with CPR) is as effective as heparin before arrest (38). We also evaluated if pulmonary congestion occurs during ECS with the heart arrested and we described an in vivo method to assess if lungs are suitable for transplantation from DCD donors following ECS resuscitation. ECS does not cause pulmonary congestion, and lungs retain adequate function for transplantation, and compliance correlated with lung function (39). Our results indicated that ECS resuscitation of DCD kidneys is feasible and allows for assessment of function prior to procurement by quantification of $U O$ and urine components in the donor. Future studies include the 
identification of the maximal cardiac arrest/warm ischemia time in which organs from DCD can be successfully resuscitated with ECS, as well as the optimization of the ECS perfusion (temperature, diuretics, n-acetylcysteine, thrombolytic agents, etc.) with the goal to minimize the ischemic reperfusion injury of DCD abdominal grafts, and/or the addition of leukocyte depletion filters to the ECS circuit. Finally, this model also creates the opportunity to improve DCD-ECS organ recovery runs with the goal to increase the ratio of functional organs per donor, including liver, lung and pancreas donation in DCD.

\section{Conclusions}

(1) Kidneys may be successfully recovered from DCD donors after 10 min of arrest/warm ischemia (but not after $30 \mathrm{~min}) ;(2)$ The use of normothermic venoarterial perfusion of oxygenated blood (ECS) can resuscitate kidneys to transplantable status after 30 min of warm ischemia in a large animal model of DCD organ donation; (3) This study adds supporting physiologic data from a large animal model to the clinical data in human DCD donors that ECS improves posttransplant outcomes.

\section{Acknowledgment}

Supported by the Division of Transplantation at the University of Michigan.

\section{References}

1. UNOS TOPATNa. OPTN. Donors recovered in the U.S. by donor type. Available at: http://www.optn.org/latestData/rptData.asp. 2008 [cited 2008 June 12th].

2. (IOM) IOM. Organ Donation: Opportunities for Action, 2006 Edn. Washington, DC: The National Academies Press, 2006.

3. Alonso A, Buitron JG, Gomez M et al. Short- and long-term results with kidneys from non-heart-beating donors. Transplant Proc 1997; 29: $1378-1380$

4. Alonso A, Fernandez-Rivera C, Villaverde P et al. Renal transplantation from non-heart-beating donors: A single-center 10-year experience. Transplant Proc 2005; 37: 3658-3660.

5. Rojas A, Chen L, Bartlett RH, Arenas JD. Assessment of liver function during extracorporeal membrane oxygenation in the nonheart beating donor swine. Transplant Proc 2004; 36: 1268-1270.

6. Garcia-Valdecasas JC, Tabet J, Valero R et al. Liver conditioning after cardiac arrest: The use of normothermic recirculation in an experimental animal model. Transpl Int 1998; 11: 424-432.

7. Aguilar A, Alvarez-Vijande R, Capdevila S, Alcoberro J, Alcaraz A. Antioxidant patterns (superoxide dismutase, glutathione reductase, and glutathione peroxidase) in kidneys from non-heartbeating-donors: Experimental study. Transplant Proc 2007; 39: 249-252.

8. Net $\mathrm{M}$, Valero $\mathrm{R}$, Almenara $\mathrm{R}$ et al. The effect of normothermic recirculation is mediated by ischemic preconditioning in NHBD liver transplantation. Am J Transplant 2005; 5: 2385-2392.

9. Magliocca JF, Magee JC, Rowe SA et al. Extracorporeal support for organ donation after cardiac death effectively expands the donor pool. J Trauma 2005; 58: 1095-1101; discussion 1101-1092.
10. Koffman G, Gambaro G. Renal transplantation from non-heartbeating donors: A review of the European experience. J Nephrol 2003; 16: 334-341.

11. Chapman J, Bock A, Dussol B et al. Follow-up after renal transplantation with organs from donors after cardiac death. Transpl Int 2006; 19: 715-719.

12. Keizer KM, de Fijter JW, Haase-Kromwijk BJ, Weimar W. Nonheart-beating donor kidneys in the Netherlands: Allocation and outcome of transplantation. Transplantation 2005; 79: 1195-1199.

13. Chang RW. Transplantation of non-heart-beating donor kidneys. Lancet 1995; 346: 322.

14. Sudhindran S, Pettigrew GJ, Drain A et al. Outcome of transplantation using kidneys from controlled (Maastricht category 3) nonheart-beating donors. Clin Transplant 2003; 17: 93-100.

15. Sanni AO, Wilson $\mathrm{CH}$, Wyrley-Birch $\mathrm{H}$ et al. Non-heart-beating kidney transplantation: 6-year outcomes. Transplant Proc 2006; 38: 3396-3397.

16. Brook NR, White SA, Waller JR, Veitch PS, Nicholson ML. Nonheart beating donor kidneys with delayed graft function have superior graft survival compared with conventional heart-beating donor kidneys that develop delayed graft function. Am J Transplant 2003; 3: 614-618

17. Daemen JH, de Wit RJ, Bronkhorst MW, Yin M, Heineman $E$, Kootstra G. Non-heart-beating donor program contributes $40 \%$ of kidneys for transplantation. Transplant Proc 1996; 28: 105-106.

18. Cho YW, Terasaki PI, Cecka JM. High kidney graft survival rates using non-heart-beating trauma donors. Transplant Proc 1998; 30: 3795-3796.

19. Butterworth PC, Taub N, Doughman TM et al. Are kidneys from non-heart-beating donors second class organs? Transplant Proc 1997; 29: 3567-3568.

20. Matsuno N, Sakurai E, Kubota K et al. Evaluation of the factors related to early graft function in 90 kidney transplants from non-heart-beating donors. Transplant Proc 1997; 29: 35693570.

21. Valero R, Cabrer C, Oppenheimer F et al. Normothermic recirculation reduces primary graft dysfunction of kidneys obtained from non-heart-beating donors. Transpl Int 2000; 13: 303-310.

22. Nicholson ML, Metcalfe MS, White SA et al. A comparison of the results of renal transplantation from non-heart-beating, conventional cadaveric, and living donors. Kidney Int 2000; 58: 25852591.

23. Sanchez-Fructuoso A, Prats Sanchez D, Marques Vidas M, Lopez De Novales E, Barrientos Guzman A. Non-heart beating donors. Nephrol Dial Transplant 2004; 19(Suppl 3): iii26-iii31.

24. Cho YW, Terasaki PI, Cecka JM, Gjertson DW. Transplantation of kidneys from donors whose hearts have stopped beating. N Eng J Med 1998; 338: 221-225.

25. Kievit JK, Oomen AP, de Vries B, Heineman E, Kootstra G. Update on the results of non-heart-beating donor kidney transplants. Transplant Proc 1997; 29: 2989-2991.

26. Matsuno N, Kozaki K, Degawa $\mathrm{H}$ et al. A useful predictor in machine perfusion preservation for kidney transplantation from non-heartbeating donors. Transplant Proc 2000; 32: 173-174.

27. Moustafellos P, Hadjianastassiou V, Roy D et al. The influence of pulsatile preservation in kidney transplantation from non-heartbeating donors. Transplant Proc 2007; 39: 1323-1325.

28. Asher J, Wilson C, Gok M et al. Factors predicting duration of delayed graft function in non-heart-beating donor kidney transplantation. Transplant Proc 2005; 37: 348-349.

29. Koyama I, Shinozuka N, Watanabe T et al. Utilization of kidneys from non-heart-beating donors by portable cardiopulmonary bypass. Transplant Proc 1997; 29: 3550-3551. 


\section{Rojas-Pena et al.}

30. Chen KH, Tsai MK, Ko WJ et al. Renal transplantation from nonheart-beating donors with extracorporeal membrane oxygenation: Preliminary results. Transplant Proc 2000; 32: 1743-1744.

31. Ko WJ, Chen YS, Chen RJ, Lai MK, Lee PH. Non-heart-beating donors under extracorporeal membrane oxygenation support. Transplant Proc 2002; 34: 2600-2601.

32. Lee CY, Tsai MK, Ko WJ et al. Expanding the donor pool: Use of renal transplants from non-heart-beating donors supported with extracorporeal membrane oxygenation. Clin Transplant 2005; 19 : 383-390.

33. Nishikido $M$, Noguchi $M$, Koga $S$ et al. Kidney transplantation from non-heart-beating donors: Analysis of organ procurement and outcome. Transplant Proc 2004; 36: 1888-1890.

34. Sanchez-Fructuoso Al, de Miguel Marques M, Prats D, Barrientos A. Non-heart-beating donors: Experience from the Hospital Clinico of Madrid. J Nephrol 2003; 16: 387-392.

35. Gravel MT, Arenas JD, Chenault R 2nd et al. Kidney transplantation from organ donors following cardiopulmonary death using extracorporeal membrane oxygenation support. Ann Transplant 2004; 9: $57-58$.

36. de Groot H, Rauen U. Ischemia-reperfusion injury: Processes in pathogenetic networks: A review. Transplant Proc 2007; 39: 481484.

37. Bloor GK, Welsh KR, Goodall S, Shah MV. Comparison of predicted with measured creatinine clearance in cardiac surgical patients. J Cardiothorac Vasc Anesth 1996; 10: 899-902.

38. Rojas A GG, Cook KE, Bartlett RH, Punch JD, Arenas JD. Role and timing of heparin during procurement of organs with Extracorporeal Life Support (ECLS). In: 8th Congress of the International Society for Organ Donation and Procurement (ISODP). 2005; Gramado, Brasil. December 4-7, 2005; 2005.

39. Reoma JL, Rojas A, Krause EM et al. Lung physiology during ECS resuscitation of DCD donors followed by in situ assessment of lung function. ASAIO J 2009; 55: 388-394. 